\title{
RAZVIJANJE LEKSIKOGRAFSKE KOMPETENCIJE KOD SREDNJOŠKOLSKIH UČENIKA FRANCUSKOG KAO STRANOG JEZIKA
}

\begin{abstract}
APSTRAKT: Rečnik predstavlja osnovno i dragoceno sredstvo za rad svakom učeniku koji uči strani jezik, kako u školskim tako i u vanškolskim okvirima, u samostalnom i celoživotnom učenju. Velikom broju učenika potrebno je, međutim, razviti svest o mnogostrukoj koristi rečnika, odnosno potrebno je obučiti ih za korišćenje raznovrsnih informacija koje različiti rečnici pružaju u situacijama kada se ne traži samo značenje neke reči. Zbog toga se u ovom radu analizira uloga rečnika u udžbeničkoj literaturi dostupnoj srednjoškolskim učenicima francuskog jezika u Srbiji, s pretpostavkom da u njoj postoje nedostaci koji bi se mogli nadomestiti odgovarajućim aktivnostima u nastavnoj praksi. Stoga je cilj rada i ukazati na nezamenljivu ulogu nastavnika u razvijanju leksikografske komeptencije učenika. Shodno potrebama, teškoćama i navikama konkretnih učenika, trebalo bi da nastavnik sugeriše upotrebu određenih rečnika i na časovima predlaže neke od aktivnosti preporučenih u glotodidaktičkoj literaturi.
\end{abstract}

Ključne reči: rečnik, leksikografska kompetencija, učenici francuskog kao stranog jezika, nastavnik, autonomija.

\section{DEVELOPING LEXICOGRAPHIC COMPETENCE OF HIGH SCHOOL STUDENTS LEARNING FRENCH AS A FOREIGN LANGUAGE}

\begin{abstract}
Dictionary is a primary and valuable tool for a foreign language student, both in and out of school, in autonomous and lifelong learning. However, many students need to develop an awareness of the multiple benefits of using dictionaries, i.e. they need to be trained to use various types of information different dictionaries provide in situations other than merely looking for the meaning of a word. Therefore, the paper analyzes the role of dictionaries in textbook literature available to high school students in Serbia learning French, assuming it has shortcomings that appropriate activities in teaching practice could compensate. Therefore, the paper aims to point to the inevitable role of teachers in the development of students' lexicographic competence. According to students' individual needs, difficulties and habits, the teacher should suggest using specific dictionaries and propose some of the activities recommended in the glottodidactic literature in class.
\end{abstract}

Key words: dictionary, lexicographic competence, French as a foreign language students, teacher, autonomy. 


\section{UVOD}

Savremeni glotodidaktičari, leksikografi i lingvisti ukazuju na značajnu ulogu rečnika, naročito jednojezičnih, u razvijanju jezičko-komunikativne i (inter)kulturne kompetencije učenika stranog jezika. Kratak prikaz tih istraživanja dajemo odmah posle uvodnih napomena.

Podstaknuti ličnim iskustvom u radu sa studentima francuskog jezika i književnosti na Filološkom fakultetu u Beogradu u poslednjih petnaest godina, kao i istraživanjem koje pokazuje da po dolasku na fakultet ,studenti nemaju razvijene leksikografske navike" (Vidić 2014: 115), u ovom radu polazimo od pretpostavke da se u preduniverzitetskom obrazovanju ne radi dovoljno na kvalitetnoj upotrebi rečnika. Zbog toga smo želeli da ispitamo ulogu rečnika u udžbeničkoj literaturi za francuski kao strani jezik dostupnoj učenicima srednjih škola u Srbiji, kako bi se, s jedne strane, ustanovili nedostaci, s druge strane ukazalo na primere koji bi mogli pozitivno da utiču na razvijanje leksikografske korisničke kompetencije.

Ova kompetencija, po definiciji koju daje J. Kostić-Tomović, podrazumeva „sposobnost delotvorne i brze upotrebe rečnika radi pronalaženja potrebne informacije o značenju ili o nekim drugim svojstvima leksema" (2017: 19). Ista autorka navodi kako samo retki korisnici leksikografsku kompetenciju razvijaju samostalno (Kostić-Tomović 2017: 20). Budući da očekujemo da analiza udžbenika pokaže da oni uglavnom ne sadrže aktivnosti za uvođenje u korišćenje rečnika, u tekstu iznosimo i predloge aktivnosti iz glotodidaktičke literature i ličnog iskustva kojima bi nastavnici francuskog jezika mogli da podstaknu sticanje leksikografskih navika kod svojih učenika/studenata.

\section{JEDNOJEZIČNI (UČENIČKI) REČNICI}

Osmišljavanje savremene nastave stranog jezika mora biti u skladu sa komunikativnim potrebama i teškoćama ciljnih učenika, koje je, što je moguće pre, potrebno osposobiti za samostalno učenje, u čemu veliku ulogu ima efikasna upotreba rečnika. U odnosu na učenike maternjeg jezika, učenike stranog jezika, koji strani jezik uče uglavnom samo u školi, nekoliko puta nedeljno (u Srbiji najčešće dva puta nedeljno po 45 minuta), odlikuje slabija sposobnost predviđanja i zaključivanja, odnosno slaba intuicija na stranom jeziku, zapažaju Ž. Binon i S. Verlend (Binon, Verlinde 2009: 42). Razvijanju navedenih sposobnosti umnogome doprinosi dobar izbor jednojezičnih rečnika, u početku najbolje učeničkih 
(dictionnaire d'apprentissage $)^{1}$, namenjenih neizvornim govornicima stranog jezika. Naime, učenici početnog i srednjeg nivoa obično koriste samo dvojezične rečnike, koji mogu biti praktično sredstvo za razumevanje tekstova, ali ne i sredstvo za razvijanje intuicije u ciljnom jeziku, koja obuhvata formulisanje hipoteza o značenju nepoznate reči (Surcouf 2010). Dvojezični rečnici nisu dovoljni ni za produkciju tekstova na stranom jeziku. Didaktizacija u učeničkim rečnicima čini ove rečnike dobrim prelaznim rešenjem (od dvojezičnog ka opštem jednojezičnom), budući da je rečnik definicija kontrolisan, a primeri su dati u kontekstu razumljivom učenicima stranog jezika, ali ne i lišenom elemenata kulture (što je često slučaj u dvojezičnim rečnicima). Učeničke rečnike karakterišu i napomene o upotrebi (remarques/notes/notice d'usage) pojedinih reči, koje mogu sadržati informacije ne samo semantičke, nego i morfološke, sintagmatske, paradigmatske i pragmatičke prirode (Binon, Verlinde 2009: 44, 46, 52), najčešće nepostojeće $\mathrm{u}$ drugim rečnicima ${ }^{2}$, a neophodne u aktivnostima koje nisu samo receptivne. Uokvirene ili na neki drugi način istaknute, na početku ili kraju rečničkog članka, ove napomene treba da privuku učenikovu pažnju (Naudts in Binon, Verlinde 2009: 52) i preduprede moguće greške.

Jedan od didaktičara koji savetuje da se rano počne s korišćenjem jednojezičnog rečnika, Ž. P. Rober, naročito preporučuje učenički rečnik Žozete Re-Debov (Rey-Debove, Dictionnaire du français - référence, apprentissage, 1999), prilagođen nefrankofonim učenicima (Robert 2008: 66), adolescentima i odraslima. Učenicima i studentima francuskog jezika obraćaju se i D. Točanac, T. Dinić i J. Vidić Francusko-srpskim rečnikom (2017: VIII), te, prirodno, koriste i ovaj francuski izvor kao uzor u radu, ne izdvajajući, ipak, napomene o upotrebi iz rečničkog članka. Kao što se može videti u izvodu 1, osim izdvojene napomene o

\footnotetext{
${ }^{1}$ O učeničkim rečnicima v. Kostić-Tomović (2017: 249) koja ih definiše i navodi termine na nemačkom i engleskom jeziku (Lernerwörterbuch, learner's dictionary). S. Verlend, T. Selva i Ž. Binon zapažaju da ima svega pet francuskih učeničkih rečnika (Verlinde et al. 2009: 289), od kojih je prvi Gugenemov Osnovni francuski rečnik (Gougenheim, Dictionnaire fondamental de la langue française, 1958) reči i izraza koji se najčešće koriste u svakodnevnom govoru.

${ }^{2} \mathrm{Da}$ bi vladao vokabularom, kako u receptivnim tako i u produktivnim aktivnostima, učenik, ističu Binon i Verlend, treba da: ,poznaje značenje leksičkih jedinica ciljnog jezika (semantička dimenzija)", zna kako se one kombinuju (sintagmatska dimenzija) i upotrebljavaju (pragmatička dimenzija), zna kako da ih razlikuje (paradigmatska dimenzija) i organizuje (Binon, Verlinde 2009: 50).
} 
upotrebi (s informacijom pragmatičke prirode) ${ }^{3}$, jednojezični učenički rečnik sadrži brojnije i bogatije primere. Na taj način učenik je više izložen stranom jeziku:

\section{Dictionnaire du français - référence, Француско-српски речник (2017) apprentissage (1999)}

ADDITION [adisjõ] n.f. UNE ADDITION addition [adisjõ] n.f. 1. сабирање · faire 1. Opération de calcul qui consiste à ajouter l’ саб(и)рати 2. рачун (у ресторану, des nombres les uns aux autres. $120+30+12$ кафеу) $\cdot L^{\prime \sim}$, s'il vous plaît. Молим вас, est une addition. $\rightarrow$ plus. Elle fait une addition. Les quatre opérations de calcul sont l'addition, la soustraction, la multiplication et la division. 2. Ce que l'on doit payer au restaurant, au café. Garçon, l'addition, s'il vous plaît! Je règle l'addition et nous partons. 3. L'ADDITION : action d'ajouter en mélangeant, dans une recette. Ce jus de fruit est préparé sans addition de sucre.

REM. Au café ou au restaurant, au moment de payer, on emploie le mot addition, mais à l'hôtel on emploie le mot note. Voir aussi facture.

Izvod 1. Članak u jednojezičnom učeničkom i u dvojezičnom rečniku

Uočava se i to da jednojezični rečnik sadrži i druge reči iz istog asocijativnog polja, a sve to doprinosi boljem memorisanju, kao i pravilnijoj upotrebi reči u aktivnostima produkcije. Asocijativna polja iz jednojezičnih rečnika doprinose i usvajanju kolokacija, naglašava M. Popović (2009: 168-169):

„Асоцијативна поља се користе и у једнојезичним речницима када се у оквиру чланка посвећеног једној речи наводе и друге речи које су у некој вези са дефинисаним појмом. Овај поступак је веома користан и због проблема колокација. Уз реч décision у речнику се наводи и глагол prendre, и тако се зна да се донети одлуку не преводи *apporter une décision већ prendre une décision."

Usvajanje kolokacija jedan je od ključnih problema u učenju stranog jezika, budući da „ученик може да погоди значење извесних колокација (у

${ }^{3}$ Uz neke druge reči, rečnik Ž. Re-Debov pruža i uokvirene napomene o lažnim prijateljima, a uz gramatičke termine - objašnjenja. 
активностима рецепције) али не и да их употреби (у активностима продукције) уколико их раније није меморисао" (Брајовић 2021: 210), što znači da „неопходно је научити и ученике да стекну навику да приликом коришћења речника уочавају колокације" (Ibid.: 211), koje su obično brojnije u jednojezičnim rečnicima.

\section{METOD}

Savremeni istraživači ukazuju na značajnu ulogu rečnika u učenju stranog jezika, posebno izdvajajući prednosti jednojezičnih rečnika. U daljem tekstu ispitujemo da li se njihove preporuke prepoznaju u udžbeničkom materijalu. Primenom deskriptivne i analitičko-komparativne metode, odnosno eksplorativnointerpretativnog postupka, na korpusu savremenih udžbenika francuskog jezika za srednju školu i dodatnog udžbeničkog materijala izdvajamo: (a) prisustvo i cilj aktivnosti koje eksplicitno pozivaju na upotrebu rečnika, (b) prisustvo analize rečničkog članka, (c) prisustvo aneksnih rečnika i (d) vrste rečnika koji se predlažu učenicima (s posebnim naglaskom na jednojezične i učeničke rečnike).

U obzir uzimamo udžbenike za srednju školu koji se nalaze u katalozima odobrenih udžbenika Ministarstva prosvete, nauke i tehnološkog razvoja, počev od 2012/13. školske godine (s napomenom da se u katalozima nalaze i udžbenici odobreni ranijih godina), odnosno udžbenike koji se koriste u našim školama, a objavljeni su u XXI veku (nekoliko naslova iz XX veka ne uvršćujemo u ovaj korpus). Reč je o udžbenicima ili udžbeničkim kompletima (s radnom sveskom i/ili priručnikom za nastavnike) objavljenim u Srbiji ili Francuskoj. U pitanju su sledeći naslovi: Le français... j'aime! za prvi i drugi razred (2007. i 2009), Quoi de neuf? za treći i za četvrti razred (2012. i 2018), Le Nouveau Taxi! 2 i 3 (2009. i 2010) i Belleville 2 i 3 (2004. i 2005) - po dva udžbenička kompleta koji se uglavnom koriste za četiri godine, Version originale na 4 nivoa (2011-2013). Korpus čine i udžbenici Panorama de la langue française 3 (1996) i Nouveau Rond-Point Pas à Pas B1.2. (2012), kao i tri naslova dodatnog materijala: Jouer, communiquer, apprendre (2002), Le chemin des mots (2004) i Écritures créatives (2011), koje učenici mogu da konsultuju u medijateci Francuskog instituta u Beogradu.

Posle analize rezultata, ukazujemo na moguće nastavnikovo postupanje, $u$ smislu korišćenja dobrih primera koji se nude u udžbeničkom materijalu i didaktičkoj literaturi. 


\section{REZULTAT I DISKUSIJA}

\subsection{Rečnici u udžbeničkoj literaturi}

Iz posmatranog i pobrojanog korpusa, izdvajamo dva udžbenika i jedan udžbenički komplet na četiri nivoa (A1-B2) u kojima ima elemenata koji nas u ovom radu zanimaju.

U udžbeniku srpskih autora za osmu godinu učenja i četvrti razred gimnazije Quoi de neuf-učenicima se predlaže korišćenje rečnika, ali se ne eksplicira način rada, niti se predlažu konkretni rečnici. Predlaže se rad na porodici reči uz pomoć rečnika (Бошковић Клос, Деспотовић Ћурчић, Маринковић 2018: 24), kao i traženje značenja pojedinih reči (Бошковић Клос, Деспотовић Ћурчић, Маринковић 2018: 11, 57), uz uočavanje i porekla reči. Uz ovaj udžbenik ne postoji priručnik za nastavnike u kojem bi se, eventualno, mogle naći preporuke za rad s rečnikom.

Upotrebi rečnika posvećena je veća pažnja u adaptacijama udžbeničkih kompleta Version originale za srpske učenike francuskog jezika u gimnazijama i stručnim srednjim školama. Kroz ceo udžbenik Version Originale 1 (namenjen učenicima prve godine učenja francuskog jezika) posebnim piktogramom sugeriše se upotreba rečnika u aktivnostima koje učenika podstiču na jednostavnu produkciju na stranom jeziku (Version Originale 1 2011: 12, 23, 24, 26, 38, 50, 67, 79) ili na razumevanje značenja reči (Version Originale 1 2011: 73, 98). Ukazuje se, takođe, na skraćenice kojima se u rečniku označava rod imenica (Version Originale 1 2011: 12), ali se time i završava eksplicitno obučavanje učenika za korišćenje rečnika. U odgovarajućem pedagoškom priručniku podstiče se upotreba raznovrsnih rečnika: dvojezičnih, štampanih ili onlajn izdanja (u okviru prve jedinice, znači na samom početku učenja jezika) i jednojezičnih - Petit Larousse illustré i Le Robert de poche, $\mathrm{s}$ predlogom da se uporede dve definicije iz ovih rečnika (Version Originale 1: Guide pédagogique, Unité 7 , str. 13). Već se u prvoj jedinici priručnika za nastavnike skreće pažnja na važnu činjenicu da rečnici sadrže brojne druge informacije pored semantičkih (Version Originale 1: Guide pédagogique, Unité 1, str. 8), ali se u samom udžbeniku ne predlažu aktivnosti kojima bi se učenici podstakli da te druge informacije prvo uoče u rečničkom članku, a zatim i samostalno traže u rečniku. Drugim rečima, nastavnik bi trebalo da osmisli rad i aktivnosti na razvijanju leksikografske kompetencije, na čiji se značaj ukazuje u priručniku. U priručniku za nastavnike udžbenika za petu i drugu godinu učenja francuskog (odnosno za prvi i drugi razred gimnazije i stručnih srednjih škola), Version Originale 2, takođe se podstiče upotreba jednojezičkih rečnika (Version Originale 2: Guide pédagogique, Unité 4, str. 12, 16), 
traženjem definicija. Aktivnosti samog udžbenika nalikuju onim iz prve knjige, s tim što se uočava i jedna aktivnost konstituisanja porodica reči (Version Originale 2 2011: 82). Na porodici reči, uz pomoć rečnika, radi se i u udžbeniku Version Originale 3 (2012: 101), dok poslednja, deveta jedinica sadrži tekst o neologizmima i ažuriranju rečnika Le Petit Robert, aktivnosti vezane za značenje i definicije reči, ali i one koje eksplicitno podstiču razmišljanje o sopstvenoj upotrebi rečnika (Version Originale 3 2012: 116), odnosno koje više podstiču razvijanje metakognitivnih učenikovih strategija nego leksikografske kompetencije. U priručniku za nastavnike, sada se predlažu rečnici Le Petit Larousse i Le Petit Robert, kao i onlajn izdanja rečnika (Version Originale 3: Guide pédagogique, Unité 9, str. 5) i opet se skreće pažnja na to da je potrebno da učenici u rečniku poznaju značenje skraćenica za rod, ali i broj i vrstu reči (Version Originale 3: Guide pédagogique, Unité 9, str. 6). U pedagoškom priručniku udžbenika Version Originale 4, kao dodatna aktivnost, predlaže se upotreba onlajn rečnika skraćenica koje se koriste u SMS porukama (Version Originale 4: Guide pédagogique, Unité 6, str. 7).

Još jedan savremeni udžbenik učenike barem delimično ,vodi” kroz korišćenje rečnika - Nouveau Rond-Point Pas à Pas B1.2. Međutim, navedeni udžbenik se ne koristi u srednjim školama, jer se ne nalazi na spisku odobrenih udžbenika Ministarstva prosvete, nauke i tehnološkog razvoja. Kako se navodi na koricama ovog udžbenika, on vodi ka brzom sticanju autonomije i nudi „savete i strategije za bolje učenje", između ostalog i aktivnostima koje učenika obučavaju i navikavaju da, na tom jezičkom nivou, prvenstveno koristi jednojezični rečnik (Flumian et al. 2012: 139). Pored eksplicitnih preporuka učenicima da praktikuju globalno razumevanje teksta i koriste rečnike kao što su Le petit Robert i Le Larousse illustré, te da sami predlože prevod reči ili izraza (u čemu vidimo nastojanje da se kod učenika razvija sposobnost zaključivanja), udžbenik sadrži i aktivnost kojom se od učenika traži da iz ponuđenog književnog teksta izdvoje deset reči, za njih predlože definiciju, a potom i prevod na maternji jezik (Flumian et al. 2012: 139). Data je i preporuka za obazrivo, neishitreno korišćenje dvojezičnog rečnika, stavljanjem naglaska na značaj konteksta u razumevanju (Ibid.): ,...dobro pročitajte sve odrednice reči kako biste bili sigurni da prevod koji ćete izabrati zaista odgovara kontekstu". U priručniku za nastavnike, na jednom mestu pronalazimo predlog da učenici u rečniku potraže antonime imenica i glagola koji bi im mogli biti korisni u traženoj usmenoj produkciji (Nouveau Rond-Point Pas à Pas B1.2 : Guide pédagogique, Unité 2, str. 9).

Više primera nalazimo u perifernom, dodatnom materijalu, uglavnom namenjenom višem jezičkom nivou. 
Autori knjige Le chemin des mots pozivaju učenike da koriste jednojezične rečnike, te da, uz pomoć rečnika Le Robert (znači ponovo opšteg, a ne rečnika za učenje jezika) pronađu: poreklo i smisao reči, prvobitni i savremeni smisao (Dumarest, Morsel 2004: 11); značenje pojedinih zajedničkih imenica nastalih od vlastitih imena ${ }^{4}$ (Ibid.: 24); porodicu reči, odnosno moguće prefikse i sufikse, uz datu pomoć u vidu broja i oblika mogućih osnova reči5 ${ }^{5}$ (Ibid.: 78).

U zbirci ludičkih aktivnosti Jouer, communiquer, apprendre dva puta se predlaže konsultovanje rečnika. U „Igri azbuke ili rečnika” (Jeu de l'alphabet ou du dictionnaire), namenjenoj učenicima koji su francuski jezik učili najmanje pet godina (odnosno 400 sati $^{6}$ ), potrebno je na papiru ispisati šest sledećih rubrika (kojima se mogu dodati i neke druge kategorije): Imena (Prénoms), Profesija ili zanimanje (Profession ou métier), Gradovi (Villes), Zemlje (Pays), Biljke (Plantes), Životinje (Animaux), a zatim ih, u ograničenom vremenskom periodu, ispuniti rečima koje počinju zadatim slovom (na primer: Marie, médecin, Marseille, Madagascar, melon, mammouth). Posle svake ispunjene rubrike, nastavnik dodeljuje po poen za pronađenu reč i tri poena za reč koju niko drugi nije pronašao. U nastavku ovog takmičarskog zadatka (gotovo identičnog edukativnoj društvenoj igri „Zanimljiva geografija”), nastavnik predlaže aktivnost kreativnog pisanja - sastaviti priču koja će sadržati šest pronađenih reči (Weiss 2002: 47). Kreativna, a manje zahtevna, jesta aktivnost nazvana „Napravite vaš rečnik!” (Faites votre dictionnaire !), namenjena učenicima koji francuski uče 200 do 400 sati (3-4 godine, odnosno 6-8 kod nas). Pošto su u rečniku pronašli definicije nekoliko nepoznatih reči, učenici treba da napišu za svaku reč po tri svoje definicije ${ }^{7}$ (Weiss 2002: 106-107).

Upotrebu jednojezičnih rečnika u aktivnostima kreativnog pisanja, počev od nivoa B1, a podstaknutim igrama književnog pokreta „Ulipo”, nalazimo i u zbirci

${ }^{4}$ Nalog i početak aktivnosti glase: „Répondez aux questions suivantes à l'aide du dictionnaire. 1. Louis de Béchamel était un financier et un gourmet très connu du XVIIe siècle. Mais qu'est-ce qu'une béchamel ? ...”

${ }^{5}$ Nalog i početak aktivnosti glase: „À l'aide d'un dictionnaire, trouvez les familles des mots simples suivants : Clair; Long; Chant (2 bases : chant - ; cant - )..."

${ }^{6} \mathrm{~S}$ obzirom na činjenicu da naš Nastavni plan predviđa da se i prvi i drugi strani jezik uče sa po 2 časa nedeljno, 72 časa godišnje ( $68 \mathrm{u}$ osmom razredu), to bi značilo da bi se ova aktivnost eventualno predložila učenicima pri kraju osme godine učenja francuskog.

${ }^{7} \mathrm{Na}$ primer, učenik pronalazi definiciju ,sreće” u rečniku (Bonheur : Etat de parfaite satisfaction intérieure), a zatim piše svoje tri definicije (Le bonheur $\rightarrow c^{\prime}$ 'est...; $\rightarrow$ c'est...; $\rightarrow c^{\prime}$ est...).

${ }^{8} \mathrm{Na}$ francuskom OuLiPo, što je akronim za naziv Ouvroir de littérature potentielle, u prevodu „Radionica za potencijalnu književnost”. 
Écritures créatives. U prvoj aktivnosti (Littérature définitionnelle), učenici u paru pišu po jednu jednostavnu rečenicu, čije će tri reči (na primer imenicu, glagol, pridev) drugi par zameniti njihovim definicijama, koje će pak ili potražiti u rečniku (i onda ih preformulisati) ili sami izmisliti (Bara, Bonvallet, Rodier 2011: 67). U toj novoj rečenici, podvlače se četiri reči, za koje neki drugi par piše definiciju, te se tako dobija nova, prilično duga i složena rečenica, u kojoj, kad se pročita, prvi par treba da prepozna početnu rečenicu. Cilj druge aktivnosti (Abécédaire) jeste kolektivno pisanje enciklopedijskog rečnika, „stvarnog, imaginarnog ili apsurdnog” (Ibid.: 68). Za svako slovo abecede, učenici biraju reč koja počinje tim slovom, za koju, u paru, daju što je moguće više komentara (objašnjavaju razloge izbora baš te reči, moguću polisemiju, citate, naslove knjiga, filmova ili pesama koje sadrže tu reč, i slično), prvo usmeno, zatim i pisano. Parovi potom razmenjuju napisane tekstove radi čitanja i korigovanja, te se oni, u papirnom ili elektronskom obliku, čuvaju cele školske godine kako bi se od njih napravio enciklopedijski rečnik odeljenja. To je, takođe, zaključuju autori zbirke, „odličan način da se memoriše vokabular” (Ibid.).

Aktivnosti uočene u perifernom materijalu podsećaju na one koje predlaže udžbenik Panorama 3, s kraja prošlog veka, namenjen starijim adolescentima i odraslim učenicima koji su francuski jezik učili 250 sati (što bi odgovaralo današnjem nivou A2/B1), a koji je svakako potrebno navesti kao dobar primer mogućeg podsticanja učenika na korišćenje rečnika. Na njegovom početku, predlaže se pisanje (i ilustrovanje) jednog ili više rečničkih članaka, prvo jezičkog, a zatim i „ličnog i originalnog" (Girardet, Frérot 1996: 12), koji bi oponašao ponuđene modele nekoliko neobičnih, maštovitih i duhovitih rečničkih članaka, pod nazivom ,izmaštani rečnik” (dictionnaire fantaisiste), „rečnik otrcanih misli ${ }^{10 ”}$ (dictionnaire des idées reçues), „rečnik uspomena” (dictionnaire des souvenirs). To znači da se učenik podsticanjem kreativnog pisanja dodatno motiviše da koristi rečnike (jer, osim što bi trebalo da bude zabavno, ono i ukazuje na višestruke uloge rečnika), ali pre svega da obrati pažnju na strukturu rečničkog članka u kojem treba da uoči elemente kao što su ,etimologija reči; različito pisanje reči tokom vekova; različita značenja reči; književni citati; različiti izrazi u kojima se pojavljuje reč iz odrednice", kao i izraze koji se ne mogu bukvalno prevesti na maternji jezik (Girardet, Frérot 1996: 12).

Strani udžbenici (početnog) nivoa A, u cilju ostvarenja plurilingvalne komeptencije kao jednog od opštih ciljeva referentne publikacije za savremeno

\footnotetext{
${ }^{9}$ Za korigovanje bi učenicima takođe trebalo ponuditi da koriste rečnike, o čemu će biti reči u sledećem poglavlju.

${ }^{10}$ Tako je, inače, kod nas prevedeno Floberovo istoimeno delo.
} 
učenje/nastavu stranog jezika - Zajedničkog evropskog okvira: učenje, nastava, ocenjivanje $(2001)^{11}$, najčešće sadrže višejezične aneksne rečnike (francusko-engleskišpanski-portugalski, a onda, u zavisnosti od rečnika, još i nemački, grčki, italijanski). U njima su popisana samo značenja reči i izraza koja se pojavljuju u kontekstima tekstova i aktivnosti iz udžbenika, ponekad samo značenje iz prvog pojavljivanja u udžbeniku. Transparentne reči najčešće se ne uvršćuju u rečnik. Uobičajeno je da ispred rečnika stoji popis korišćenih skraćenica. Osim višejezičnog rečnika, udžbenik Le Nouveau Taxi ! 2, namenjen nivou A2, ima i tematski rečnik, samo na francuskom, s odrednicama kao što su „ishrana”, „kultura”, „obrazovanje”, itd., čija je funkcija, ističu autori, da olakša memorisanje reči i da pospeši njihovo aktivno učenje (Menand 2009: 107), ali nema ponuđenih aktivnosti koje će se jasno dovesti u vezu s rečnikom i njegovom funkcijom. U sledećoj knjizi istog udžbenika, Le Nouveau Taxi! 3, nema nikakvog rečnika, kao ni u drugim stranim udžbenicima nivoa B, što ukazuje na želju autora da učenike podstaknu na samostalno korišćenje rečnika.

Dvojezične aneksne rečnike nalazimo u udžbenicima domaćih autora - Le français... j’aime! (prvi i drugi razred) i Quoi de neuf ? (treći i četvrti razred), dok Version originale ne sadrži rečnik.

Analiza udžbeničkog materijala pokazuje da se rečnik pominje u jednom savremenom srednjoškolskom udžbeniku domaćih autora, da neke smernice za korišćenje rečnika pruža udžbenik koji bi se mogao koristiti u vanškolskom učenju/nastavi na nivou B1 (jer za školsku nastavu nije odobren), da udžbenički komplet Version originale na četiri nivoa podstiče upotrebu rečnika, a da podsticajnije i raznovrsnije predloge sadrži dodatni materijal. Učenici se, međutim, ni na jednom mestu ne upućuju na korišćenje učeničkih rečnika, niti se predlaže detaljna analiza rečničkih članaka (kao što je to urađeno u udžbeniku Panorama 3 iz 1996). Kada se u aktivnostima predlaže korišćenje rečnika, dvojezičnih ili opštih jednojezičnih, to je uglavnom radi semantizacije, rada na porodici ili etimologiji reči. Budući da predložene aktivnosti ne podstiču otkrivanje i drugih informacija koje rečnik pruža prilikom učenja stranog jezika, udžbenici za francuski kao strani jezik koje trenutno koriste učenici srednjih škola u Srbiji ne doprinose dovoljno razvoju veštine upotrebe rečnika $^{12}$, čak ni aneksnih rečnika koje mnogi udžbenici sadrže. Stiče se utisak da je

\footnotetext{
${ }^{11}$ Prevod dokumenta Cadre européen commun de référence pour les langues: apprendre, enseigner, évaluer (CECR) objavljen je u Crnoj Gori pod nazivom Zajednički evropski okvir: učenje, nastava, ocjenjivanje (2003). O pominjanju rečnika u ovoj publikaciji v. Grabowska (2016).

12 Isto zapažanje iznosi i J. Kostić-Tomović vezano za udžbeničke komplete za nemački, u školskoj i vanškolskoj nastavi u Srbiji (2017: 24).
} 
postojanje dvojezičnih aneksnih rečnika u domaćim udžbenicima, namenjenim čak i adolescentima koji francuski jezik uče više od četiri godine, prevashodno motivisano komercijalnim razlogom. Ukoliko već postoje, bilo bi bolje kad bi sadržali čitave rečenice-primere, a ne samo izolovane reči (onako kako je to uglavnom urađeno $\mathrm{u}$ pomenutom Francusko-srpskom rečniku iz 2017. godine) ${ }^{13}$, kao i poneku napomenu o upotrebi. S druge strane, pojedinim prevodima iz udžbeničkih rečnika, izvedenim iz, najčešće, savremenih tekstova, leksikografi bi mogli dopuniti standardne dvojezične rečnike u upotrebi.

\subsection{Predlozi aktivnosti u funkciji podsticanja leksikografskih navika}

Kako bi učenici stekli naviku da koriste rečnik/e, ,naročito da ga/ih koriste često" (Cavalla et al. 2010: 38), važno je, između ostalog, eksplicitno objasniti kako „efikasno čitati članak”, naglašavaju Baron i Bertran (Baron, Bertrand 2012: [1]), što bi značilo da bi bilo dobro da se učenicima već u udžbenicima nivoa A2, ili najkasnije B1, pokaže struktura članka u nekom jednojezičnom rečniku. Ovo je urađeno u pomenutom udžbeniku objavljenom pre dvadeset pet godina - Panorama 3. U nedostatku takve didaktičke aparature u samom udžbeniku, a nedostatak smo ustanovili pregledom savremene udžbeničke literature dostupne srpskim učenicima, nastavnik može i sam da izabere rečničke članke za analizu, imajući na umu konkretnu grupu učenika koju ima pred sobom. Engelberg i Lemnicer naglašavaju da prilikom razvijanja leksikografske korisničke kompetencije „treba poći od konkretnih jezičkih problema i tako upoznavati učenike sa funkcijom i strukturom rečnika, dok vežbe u kojima je upotreba rečnika sama sebi svrha treba izbegavati" (Engelberg-Lemnitzer u Kostić-Tomović 2017: 22). Nastavnik francuskog jezika mogao bi, na primer, da počne od glagola aider, budući da izbor predloga uz ovaj glagol srpskim učenicima često predstavlja problem, to jest da objasni upravo taj rečnički članak i da učenicima skrene pažnju na to da je uvek dobro proveriti u rečniku sintaksičku konstrukciju reči ${ }^{14}$. Učenici bi, najpre, posmatrali članak koji se odnosi na glagol: polazni rečnički oblik,

\footnotetext{
${ }^{13}$ Nešto slično primećeno je u udžbeniku Francuski jezik za I razred srednje škole (Kostić, Perret 1995) za prvu godinu učenja, koji ne sadrži uobičajeni francusko-srpski aneksni rečnik nego prevod reči u kontekstu, odnosno prevod čitavih rečenica, sa izgovorom (fonetskom transkripcijom) i bez gramatičkih oznaka i kvalifikatora.

${ }^{14}$ Naveli smo primer glagola, ali to mogu biti i pridevi i imenice, za koje Verlend, Binon i Selva (Verlinde, Binon, Selva 2006: 88) navode tri primera (bon en qqch., apte à faire qqch., l'approvisionnement en qqch.), uz zapažanje da se informacije o sintagmatskim odnosima u rečnicima obično pronalaze samo implicitno, u primerima, osim oznake da su glagoli neprelazni ili prelazni (direktno i indirektno).
} 
izgovor, gramatičku oznaku, definiciju i primere. U Izvodu 2, primetićemo da je u ovom slučaju srpskim učenicima korisniji dvojezični rečnik, budući da se u njemu nalazi primer koji jasnije ukazuje na nepostojanje predloga iza glagola u značenju „pomoći (nekome)”, što će, u drugoj etapi rada s rečnikom, omogućiti zamenu imenice odgovarajućom zamenicom, u čijoj upotrebi učenici upravo i greše, pod uticajem maternjeg jezika.

\begin{tabular}{|c|c|}
\hline $\begin{array}{l}\text { Dictionnaire } d u \text { français }- \text { référence, } \\
\text { apprentissage (1999) }\end{array}$ & Франиуско-српски р \\
\hline $\begin{array}{l}\text { AIDER [ede] verbe [conjugaison 1a] } \\
\text { I. Apporter son aide à qqn en } \\
\text { joignant ses efforts aux siens. } \\
\text { Prenez ma main, je vais vous } \\
\text { aider à vous relever. Pouvez-vous } \\
\text { m'aider? Aidez-moi! Je vais } \\
\text { t'aider à finir la vaisselle. Vos } \\
\text { conseils m'ont beaucoup aidée. } \\
\text { II. Verbe pronominal S'AIDER } \\
\text { DE : se servir de. Elle s'est aidée } \\
\text { de ses mains pour grimper sur le } \\
\text { rocher. J'ai dû m'aider du } \\
\text { dictionnaire pour trouver } \\
\text { l'orthographe de ce mot. }\end{array}$ & $\begin{array}{l}\text { aider [ede] v. tr. помоћи, помагати • } \\
q q n \text { à faire qqch помагати неком да } \\
\text { уради нешто · Je vais ma grand-mère } \\
\text { à traverser la rue. Помоћи ћу баки да } \\
\text { пређе улицу. } \diamond v \text {. tr. ind. допринети · } \\
\text { au succès d'une entreprise допринети } \\
\text { успеху предузећа } \diamond s \text {, потпомогнути } \\
\text { се, припомогнути се, помагати се · } s \text {, } \\
\text { de ses mains потпомоћи се рукама. }\end{array}$ \\
\hline
\end{tabular}

Izvod 2. „Problematični” glagol aider u (štampanom) učeničkom jednojezičnom i dvojezičnom rečniku

Usledili bi jezički zadaci, u zavisnosti od jezičkog nivoa učenika, recimo: u primeru iz članka Je vais aider ma grand-mère à traverser la rue zameniti imenicu grand-mère zamenicom; objasniti slaganje participa perfekta u primeru Vos conseils m'ont beaucoup aidée; ispraviti u rečenicama koje nastavnik predloži (možda iz učeničkih radova) greške u glagolskoj konstrukciji, što bi trebalo - smatraju Baron i Bertran (Baron, Bertrand 2012: [2]) - da podstakne učenika da obraća više pažnje na tu vrstu grešaka u svojim pisanim radovima. Učenicima je potrebno razviti i naviku da koriste rečnike prilikom rada na proveri ispravnosti sopstvenih pisanih radova. 
U didaktičkoj literaturi frankofonih autora pronalazimo sledeće predloge aktivnosti kojima bi se učenici ohrabrili da koriste jednojezične rečnike, osposobili za njihovo korišćenje i uvideli kakve informacije u kom rečniku mogu da pronađu ${ }^{15}$ :

- izrada sopstvenog rečnika, s kontekstualizovanom upotrebom reči (Tréville, Duquette 1996: 123-124; Cuq, Gruca 2013: 409);

- traženje u rečniku značenja nepoznatih reči (Cavalla et al. 2010: 99) i porodice reči (Cavalla et al. 2010: 203-204);

- kreiranje karte proučavanja reči (koja sadrži nepoznatu reč u rečenici u kojoj je viđena, zatim podatke iz rečnika - definiciju, po jedan sinonim i antonim koji odgovaraju kontekstu, porodicu reči, sopstveni primer rečenice koja bi sadržala tu reč) i kolektivna aktivnost kreiranja veb-glosara ${ }^{16}$ (Baron, Bertrand 2012: [36]);

- traženje određene reči ili izraza u dva jednojezična rečnika i jednom dvojezičnom i uočavanje razlika u količini i vrsti informacija (Tréville, Duquette 1996: 127-128).

U vezi sa poslednjim predlogom, nastalim pre četvrt veka, smatramo da bi korisno bilo ponuditi učenicima i poređenje rečničkih članaka posvećenih istoj odrednici uzetih iz jednog opšteg i jednog učeničkog jednojezičnog rečnika. Na taj način učenici bi uvideli da je odlika prvog članka iscrpnost (s čestim primerima iz književnih tekstova), a drugog rečničkog članka jednostavnost. Učenicima bi trebalo predstaviti i članak iz nekog internetskog rečnika, budući da su oni učenicima najdostupniji. Prikazom rečničkih članaka iz opšteg i internetskog rečnika u Izvodu 3, dopunićemo, zapravo, prethodni Izvod 2. Uz napomenu da bi se učenicima prikazali celi članci, u ovom tekstu ćemo ih skratiti - u prvom prikazujemo samo početni deo, posvećen glagolu, a izostavljamo ostatak koji sadrži porodicu reči (aider, aide, aideau, aide-mémoire,

${ }^{15} \mathrm{Kad}$ je reč o nefrankofonim autorima, pozivajući se na K. Končarević i B. Stankovića, Pavlović-Šajtinac iznosi predloge vežbanja koja bi učenike ruskog jezika usmerila na korišćenje školskog rečnika pre svega (Павловић-Шајтинац 2016: 60-63), ali koja se svakako mogu prilagoditi i učenju drugih stranih jezika, jednako kao i predlozi koje KostićTomović navodi iz jedne radne sveske za nemački jezik (Kostić-Tomović 2017: 24).

16 Nastavnik iz teksta koji je izabrao za čitanje pravi listu reči ili izraza koji mogu predstavljati problem učenicima; svaki učenik bira po jednu reč koju će obraditi po zadatom modelu - traženi elementi su gramatička kategorija, rod i broj, postupak građenja reči, značenje elemenata ili afiksa koji čine reč, moguća značenja i reči iste porodice; učenici prilikom prvog čitanja rade na globalnom razumevanju teksta, a ako posle drugog čitanja ne poznaju neku reč, konsultuju ,članak” koji je uradio neki njihov drug, i vrednuju ga, govoreći koliko im je pomogao u razumevanju reči. 
entraider (s'), entraide, sous-aide); u drugom, u kojem nema transkripcije, ali se može čuti izgovor, ostavljamo definicije, izraze i napomenu o upotrebi glagolskih konstrukcija, uvedenu naslovom „Teškoće”, a izostavljamo sinonime, antonime, homonime i citate.

\begin{tabular}{|c|c|}
\hline Lexis Larousse de la langue française (2002) & Larousse.fr ${ }^{17}$ \\
\hline AIDER [ede] v. tr. (lat. adjutare; 1080). Aider & aider \\
\hline quelqu'un à (et l'inf.), dans (et un nom), & verbe transitif \\
\hline joindre ses efforts aux siens afin d'agir dans & (ancien français aidier, du latin adjutare) \\
\hline une circonstance donnée : Quelqu'un qui nous & DÉFINITIONS \\
\hline guide, qui nous aide à voir clair en nous-même & Apporter son concours à quelqu'un, joindre \\
\hline (Aragon). Il a besoin d'être aidé dans ce & ses efforts aux siens dans ce qu'il fait; lui être \\
\hline travail. (syn. ÉPAULER, SECONDER, & utile, faciliter son action, en parlant de \\
\hline SECOURIR). Les entreprises ont dî être & quelque chose : Aider un ami à surmonter ses \\
\hline aidées par l'État (syn. SOUTENIR, & difficultés. \\
\hline SUBVENTIONNER). Peu à peu, l'exemple & Apporter un soutien financier à quelqu'un, à \\
\hline aidant, les mêmes auditeurs se décidèrent à & une entreprise : Ces subventions doivent aider \\
\hline entrer (Camus). $\diamond$ v. tr. ind. Aider à une chose, & les industries en difficulté. \\
\hline la faciliter: La présence de ces personnalités & EXPRESSIONS \\
\hline dans le comité de patronage aidera à la & Ça aide, expression familière indiquant que \\
\hline réussite de notre projet (syn. CONTRIBUER & quelque chose est important, sert beaucoup. \\
\hline $\begin{array}{l}\grave{A}, \text { FAVORISER). Ces notes aident à la } \\
\text { compréhension du texte. } \diamond \text { s'aider v. pr. }\end{array}$ & $\begin{array}{l}\text { La fatigue, le temps, etc., aidant, du fait de la } \\
\text { fatigue, grâce au temps, etc. }\end{array}$ \\
\hline S'aider d'une chose, s'en servir, en tirer parti : & {$[\ldots]$} \\
\hline Il s'aide uniquement de ses mains pour & DIFFICULTÉS \\
\hline grimper à la corde. S'aider d'un dictionnaire & CONSTRUCTION \\
\hline pour traduire un texte. Aide-toi, le ciel & Aider qqn : construction courante \\
\hline t'aidera. $[\ldots]$ & REMARQUE \\
\hline & $\begin{array}{l}\text { Aider à qqn est une tournure littéraire, } \\
\text { courante à l'époque classique, mais } \\
\text { aujourd'hui sortie de l'usage. «Aucun n'aide }\end{array}$ \\
\hline & aux chevaux à se tirer d'affaire. » (La \\
\hline & Fontaine) \\
\hline & {$[\ldots]$} \\
\hline
\end{tabular}

Izvod 3. „Problematični” glagol aider u (štampanom) opštem jednojezičnom i onlajn rečniku

Na osnovu navedenog primera obrade reči u onlajn rečniku, zaključujemo da bi upravo ovaj rečnik najviše odgovarao potrebama srpskih učenika koji uče

${ }^{17}$ Konsultovano 17. 1. 2021. na: https://www.larousse.fr/dictionnaires/francais/aider/1846 
francuski jezik, odnosno da on nudi objašnjenje za upotrebu glagola „pomoći (nekome)", s primerom, u istaknutoj napomeni, uz sve druge korisne i pregledno date informacije, kao i izuzetno značajnu mogućnost besplatnog i lako dostupnog korišćenja. Poželjno je, naravno, da nastavnik predloži referentne onlajn rečnike, na primer Larusov i Roberov rečnik (https://www.larousse.fr/dictionnaires/ francais-monolingue; https://dictionnaire.lerobert.com/), a za naprednije učenike/studente francuskog jezika i najznačajniji rečnik XX veka - Trésor de la langue française (http://atilf.atilf.fr/tlfi.htm), kao i Akademijin rečnik (http://www.academie-francaise.fr/).

\section{ZAKLJUČAK}

Najznačajniji zadatak savremenog nastavnika stranog jezika jeste osposobljavanje učenika za samostalni rad, što se, između ostalog, postiže podsticanjem upotrebe rečnika. Pregledom savremenih udžbenika za francuski jezik za srednju školu u Srbiji, došli smo do zaključka da oni ne doprinose dovoljno razvoju veštine upotrebe rečnika, ali i da se iz dodatnog materijala, uglavnom namenjenom višem jezičkom nivou, mogu izdvojiti i učenicima prilagoditi pojedine aktivnosti koje traže i upotrebu rečnika. U udžbeničkoj literaturi pomenuti dvojezični i, najčešće, opšti jednojezični rečnici (nažalost nikada učenički) najčešće imaju ulogu pomoćnog sredstva u semantizaciji. Obično se učenici podstiču da traže definicije u rečniku, a zatim i da samostalno definišu (semantizuju na ciljnom jeziku), na kraju, ponekad, i da prevode. Nismo pronašli nijednu aktivnost kojom se analizira struktura rečničkog članka, a potom predlaže i njegovo pisanje (pisanje ne samo definicije, nego celog članka, s primerima i kolokacijama); takve aktivnosti ukazale bi i na informacije koje nisu samo semantičke prirode, a dragocene su ne samo za učenje reči i aktivnosti recepcije, nego i za produkciju, ali i važnu etapu provere sopstvenih pisanih radova, kojom se kod učenika razvijaju metakognitivne strategije, neophodne u samostalnom radu. Nismo pronašli ni aktivnosti koje bi kod učenika razvijale naviku da u rečniku uočavaju kolokacije, niti se u adaptacijama udžbeničkog kompleta Version originale ili udžbenicima domaćih autora vodi računa o teškoćama srpskih učenika tako što bi se one pokušale otkloniti efikasnom analizom ciljanih rečničkih članaka i odgovarajućim propratnim vežbama. U dodatnom materijalu uočili smo, međutim, traganje za motivišućim načinima da se kod učenika stvori navika korišćenja rečnika - predlaganjem igara i kreativnog pisanja, pri čemu upotreba rečnika nije „sama sebi svrha”, kao i predlaganje kolaborativnog stvaranja rečnika. Nastavnik stoga ima veoma značajan zadatak da, polazeći od jezičkih potreba i 
teškoća svojih učenika, nadomesti uočene nedostatke udžbenika, da iz priručnika za nastavnike i dodatnog materijala iskoristi poneki predlog, istovremeno razvijajući kod svojih učenika svest o značaju samostalnog korišćenja rečnika, neizostavnog sredstva u celoživotnom učenju jezika.

U nastavu francuskog jezika u našim školama neophodno je, takođe, više uključiti jednojezične rečnike, što ne znači da dvojezične treba isključiti iz procesa učenja, između ostalog i zato što ponekad sadrže informacije koje su upravo relevantne za učenike za koje su primeri birani i prevođeni. Autori dvojezičnih rečnika neretko poznaju teškoće učenika, kao što je nedovoljno vladanje kolokacijama ili sintaksičkim konstrukcijama (informacije sintagmatske prirode), ili upotreba reči adekvatna komunikativnoj situaciji (pragmatička informacija). Drugim rečima, nastavnik treba da stimuliše upotrebu različitih tipova rečnika, možda najviše pojedinih, lako dostupnih onlajn rečnika, onih s kvalitetnim opisom, što znači rečničkim člancima u kojima se stavlja akcenat na uočene teškoće učenika pri učenju i savladavanju stranog jezika.

\section{LITERATURA}

Baron, A., Bertrand, J. (2012). Utiliser le dictionnaire monolingue en classe de langue. Pristupljeno 16. 1. 2020. URL : <http://correspo.ccdmd.qc.ca/ index.php/document/cinq-pistes-pour-favoriser-le-developpement-descompetences-a-lecrit/utiliser-le-dictionnaire-monolingue-en-classe-delangue/> .

Binon, J., Verlinde, S. (2009). La contribution de la lexicographie pédagogique du français langue étrangère ou seconde (FLES) à la dictionnairique du français langue maternelle (FLM), in Pour l'amour des mots. Glanures lexicales, dictionnairiques, grammaticales et syntaxiques. Hommage à Michèle Lenoble-Pinson, Textes réunis par M. Willems (Bruxelles: Facultés universitaires Saint-Louis): 39-59.

Брајовић, Ј. (2021). Комуникативно-акииони модел наставе франиуског као страног језика. Београд: Филолошки факултет Универзитета. [Brajović, J. (2021). Komunikativno-akcioni model nastave francuskog kao stranog jezika. Beograd: Filološki fakultet Univerziteta].

Cavalla, C., Crozier, E., Dumarest, D., Richou, C. (2010). Le vocabulaire en classe de langue. Paris: CLE International.

Cuq, J.-P., Gruca, I. (2013). Cours de didactique du français langue étrangère et seconde. Grenoble: Presses Universitaires de Grenoble. 
Grabowska, M. (2016). Les dictionnaires dans l'apprentissage du FLE en Pologne: état des lieux, in Acta Universitatis Wratislaviensis, Romanica Wratislaviensia, LXIII: 53-67.

Kostić-Tomović, J. (2017). Savremena nemačka leksikografija. Beograd: FOCUS Forum za interkulturnu komunikaciju.

Павловић-Шајтинац, М. (2016). Лексикографија школских речника руског језика у српској и хрватској говорној и социокултурној средини [докторска дисертација] Pristupljeno 14. 2. 2020. URL: $<$ http://phaidrabg.bg.sc.rs/o:12723> [Pavlović-Šajtinac, M. (2016). Leksikografija školskih rečnika ruskog jezika u srpskoj $i$ hrvatskoj govornoj i sociokulturnoj sredini [doktorska disertacija] Pristupljeno 14. 2. 2020. URL: <http://phaidrabg.bg.sc.rs/o:12723>]

Поповић, М. (2009). Лексичка структура франиуског језика: морфологија и семантика. Београд: Завод за уџбенике. [Popović, М. (2009). Leksička struktura francuskog jezika: morfologija i semantika. Beograd: Zavod za udžbenike].

Robert, J.-P. (2008). Dictionnaire pratique de didactique du FLE. Paris: Ophrys.

Surcouf, Ch. (2010). Le dictionnaire bilingue peut-il s'intégrer profitablement dans une stratégie d'apprentissage d'une langue étrangère ? Pristupljeno 10. 1. 2020. URL: 〈http://journals.openedition.org/apliut/982>.

Tréville, M.-C., Duquette, L. (1996). Enseigner le vocabulaire en classe de langue. Paris: Hachette FLE.

Verlinde, S., Binon, J., Selva, T. (2006). Corpus, collocations et dictionnaires d'apprentissage. Langue française 150: 84-98.

Verlinde, S., Selva, T., Binon, J. (2009). La Base lexicale du français (BLF) : de la lexicographie de l'apprentissage à l'environnement d'apprentissage, in Le dictionnaire maître de langue: Lexicographie et didactique, éd. M. Heinz (Berlin: Frank \& Timme Gmbh Verlag für wissenschaftliche Literatur): 289-306.

Vidić, J. (2014). Rečnik u nastavi francuskog jezika za akademske potrebe. Komunikacija i kultura online 5: 102-131.

\section{LEKSIKOGRAFSKI IZVORI}

Dico en ligne Le Robert. Pristupljeno 17. 1. 2021. URL: $<$ https://dictionnaire.lerobert.com/>

Dictionnaire de l'Académie française. Pristupljeno 17. 1. 2021. URL: $<$ http://www.academie-francaise.fr/> 
Dictionnaire Français en ligne - Larousse. Pristupljeno 17. 1. 2021. URL: <https://www.larousse.fr/dictionnaires/francais-monolingue>

Lexis Larousse de la langue française (2002). Paris : Larousse.

Rey-Debove, J. (1999). Dictionnaire du français - Référence/Apprentissage.

Paris : Dictionnaires Le Robert et Clé International.

Точанац, Д., Динић, Т., Видић, J. (2017). Франиуско-српски речник. Београд: Завод за уџбенике. [Točanac, D., Dinić, T., Vidić, J. (2017). Francuskosrpski rečnik. Beograd: Zavod za udžbenike].

Trésor de la Langue Française informatisé. Pristupljeno 17. 1. 2021. URL: http://atilf.atilf.fr/tlfi.htm

\section{UDŽBENICI I UDŽBENIČKI KOMPLETI}

Бошковић Клос, С., Деспотовић Ћурчић Т., Јовановић, В. (2012). Quoi de nеuf ?, франиуски језик за 3. разред гимназије: уцбеник и радна свеска. Београд: Завод за уџбенике. [Bošković Klos, S., Despotović Ćurčić T., Jovanović, V. (2012). Quoi de neuf ?, francuski jezik za 3. razred gimnazije: udžbenik i radna sveska. Beograd: Zavod za udžbenike].

Бошковић Клос, С., Деспотовић Ћурчић Т., Маринковић, С. (2018). Quoi de nеuf: франиуски језик за 4. разред гимназије: уибеник и радна свеска. Београд: Завод за уџбенике. [Bošković Klos, S., Despotović Ćurčić T., Marinković, S. (2018). Quoi de neuf: francuski jezik za 4. razred gimnazije: udžbenik i radna sveska. Beograd: Zavod za udžbenike].

Gallier, Th., Grand-Clément, O. (2004). Belleville 2: méthode de français. Paris : CLE International/Sejer.

Grand-Clément, O., Volte, A., Gallier, Th., Moore, V. (2005). Belleville 3: méthode de français. Paris : CLE International/Sejer.

Гудурић, С., Баратовић, Ж., Топољски, А. (2007). Le français... j’aime!: француски језик за I разред средње школе (гимназије и средње стручне школе): I страни језик. Београд: Завод за уџбенике. [Gudurić, S., Baratović, Ž., Topoljski, A. (2007). Le français... j’aime !: francuski jezik za I razred srednje škole (gimnazije i srednje stručne škole): I strani jezik. Beograd: Zavod za udžbenike].

Гудурић, С., Баратовић, Ж., Топољски, А. (2007). Le français... j’aime!: француски језик за I разред средње школе (гимназије и средње стручне школе): радна свеска: I страни језик. Београд: Завод за уџбенике. [Gudurić, S., Baratović, Ž., Topoljski, A. (2007). Le français... 
j'aime !: francuski jezik za I razred srednje škole (gimnazije i srednje stručne škole): radna sveska: I strani jezik. Beograd: Zavod za udžbenike].

Гудурић, С., Баратовић, Ж., Топољски, А. (2009). Le français... j’aime! 2: француски језик за II разред средње школе (гимназије и средње стручне школе): І страни језик. Београд: Завод за уџбенике. [Gudurić, S., Baratović, Ž., Topoljski, A. (2009). Le français... j'aime! 2: francuski jezik za II razred srednje škole (gimnazije i srednje stručne škole): I strani jezik. Beograd: Zavod za udžbenike].

Гудурић, С., Баратовић, Ж., Топољски, А. (2009). Le français... j’aime! 2: француски језик за II разред средње школе (гимназије и средње стручне школе): радна свеска: I страни језик. Београд: Завод за уџбенике. [Gudurić, S., Baratović, Ž., Topoljski, A. (2009). Le français... j'aime! 2: francuski jezik za II razred srednje škole (gimnazije i srednje stručne škole): radna sveska: I strani jezik. Beograd: Zavod za udžbenike].

Flumian, C., Labascoule, J., Priniotakis, S., Royer, C., Conseil pédagogique et révision Puren, Ch. (2012). Nouveau Rond-Point Pas à Pas B1.2. Paris : Éditions Maison des langues.

Girardet, J., Frérot, J.-L. (1996). Panorama de la langue française 3: méthode de français. Paris : CLE International.

Костић, В., Perret, М. (2003). Франиуски језик за I разред средње школе други страни језик - прва година учења. Београд: Завод за уџбенике и наставна средства. [Kostić, V., Perret, M. (2003). Francuski jezik za I razred srednje škole drugi strani jezik - prva godina učenja. Beograd: Zavod za udžbenike i nastavna sredstva].

Menand, R., avec la participation d'A. Berthet et de V. Kizirian. (2009). Le Nouveau Taxi! 2: méthode de français. Paris : Hachette Livre.

Menand, R., Johnson, A.-M., avec la collaboration d'A. Berthet, N. Hirschsprung et de F. Kite. (2010). Le Nouveau Taxi! 3 : Méthode de français. Paris : Hachette Livre.

Nouveau Rond-Point Pas à Pas B1.2 : Guide pédagogique. Paris : Éditions Maison des langues. Pristupljeno 7. 7. 2021. URL: <https://espacevirtuel.emdl.fr/ courses/nouveau_rond_point_pas_a_pas_4/course_modules/ressources?group _id=\&expanded_ids\%5B \%5D=4e35abb6-4fdb-49f3-9fca-7cdb9cf2db7c>

VERSION Originale 1: франиуски језик: уцбеник и радна свеска за први разред гимназија и стручних средњих школа (прва година учења) / [приредила] Б. Николић. (2011). Београд: Klett. [VERSION Originale 1 : francuski jezik: udžbenik i radna sveska za prvi razred gimnazija i stručnih 
srenjih škola (prva godina učenja) / [priredila] B. Nikolić (2011). Beograd: Klett].

VERSION Originale 1 : guide pédagogique. Paris : Éditions Maison des langues. Pristupljeno 7. 7. 2021. URL: https://espacevirtuel.emdl.fr/courses/versionoriginale-

1/course_modules/ressources?group_id=\&expanded_ids\%5B $\% 5 \mathrm{D}=\mathrm{e} 5232 \mathrm{f}$ 84-6ed6-43dc-b0a7-807ae313ea62

VERSION Originale 2 : méthode de français: niveau 2: франиуски језик: уцбеник и радна свеска за први разред гимназија и стручних средњих школа (пета година учења): и други разред гимназија и стручних средњих школа (друга година учења) / [ауторке адаптације] Ј. Међедовић, А. Никодијевић (2011). Београд: Klett. [VERSION Originale 2 : méthode de français: niveau 2: francuski jezik: udžbenik i radna sveska za prvi razred gimnazija i stručnih srednjih škola (peta godina učenja): $i$ drugi razred gimnazija i stručnih srednjih škola (druga godina učenja) / [autorke adaptacije] J. Međedović, A. Nikodijević. (2011). Beograd: Klett].

VERSION Originale 2 : Guide pédagogique. Paris: Éditions Maison des langues. Pristupljeno 7. 7. 2021. URL: https://espacevirtuel.emdl.fr/courses/versionoriginale-

2/course_modules/ressources?group_id=\&expanded_ids\%5B $\% 5 \mathrm{D}=2 \mathrm{f} 51 \mathrm{~b} 5$ e7-f031-40b7-957b-c1d1016db1d4

VERSION Originale 3 : франиуски језик: [niveau 3]: уибеник и радна свеска за 2. разред гимназија и средњих стручних школа (шеста година учења) u 3. $и$ 4. разред гимназија и средњих стручних школа (трећа и четврта година учења) / [ауторке адаптације] Д. Милошевић, М. Милановић (2012). Београд: Klett. [VERSION Originale 3 : francuski jezik: [niveau 3]: udžbenik i radna sveska za 2. razred gimnazija i srednjih stručnih škola (šesta godina učenja) $i$ 3. $i$ 4. razred gimnazija i srednjih stručnih škola (treća i četvrta godina učenja) / [autorke adaptacije] D. Milošević, M. Milanović (2012). Beograd: Klett].

VERSION Originale 3 : Guide pédagogique. Paris: Éditions Maison des langues. Pristupljeno 7. 7. 2021. URL: https://espacevirtuel.emdl.fr/courses/versionoriginale-

3/course_modules/ressources?group_id=\&expanded_ids\%5B $\% 5 \mathrm{D}=331 \mathrm{~d} 5$ 884-6ed1-4be4-8e33-926e21a6ba25

VERSION Originale violet : франиуски језик: ниво 4: уцбеник и радна свеска за 3. и 4. разред гимназија (први страни језик) / [ауторке адаптације] Д. 
Милошевић, М. Милановић. (2012). Београд: Klett. [VERSION Originale violet : francuski jezik: nivo 4: udžbenik i radna sveska za 3. i 4. razred gimnazija (prvi strani jezik) / [autorke adaptacije] D. Milošević, M. Milanović (2012). Beograd: Klett].

VERSION Originale 4 : Guide pédagogique. Paris: Éditions Maison des langues.

Pristupljeno 7. 7. 2021. URL: https://espacevirtuel.emdl.fr/courses/versionoriginale-

4/course_modules/ressources?group_id=\&expanded_ids\%5B $\% 5 \mathrm{D}=3 \mathrm{fc} 4 \mathrm{e} 9$ 48-34d6-4835-b53a-68a85710fe93

Volte, A. (2004). Belleville 2 : cahier d'exercices. Paris : CLE International/Sejer.

\section{DODATNI MATERIJAL}

Bara, S., Bonvallet, A.-M., Rodier, Ch. (2011). Écritures créatives. Grenoble : Presses universitaires de Grenoble.

Dumarest, D., Morsel, M.-H. (2004). Le chemin des mots. Grenoble: Presses Universitaires de Grenoble.

Weiss, F. (2002). Jouer, communiquer, apprendre. Paris : Hachette.

Jelena Brajović

University of Belgrade

Faculty of Philology, Department of Romance Studies

\section{DEVELOPING LEXICOGRAPHIC COMPETENCE OF HIGH SCHOOL STUDENTS LEARNING FRENCH AS A FOREIGN LANGUAGE}

\section{Summary}

The most important task of a modern foreign language teacher is to make students as autonomous as possible. This is achieved by, among other things, encouraging students to use dictionaries. Many students need to be explicitly told about the multiple benefits of dictionary use, i.e. they need to be trained to use various types of information in a variety of dictionaries. The paper aims to show that a teacher has a unique role in developing lexicographic competence. It also aims to offer teachers some guidelines for work, mainly derived from the didactic literature. The author summarized the vital role of the teacher after analyzing the role of dictionaries in textbook literature available to French language students in Serbia. By reviewing secondary school textbooks, the author realized that they do not contribute enough to the development of dictionary usage skills, while additional material can be used to adapt a particular dictionary through required activities for students. In the textbook literature, the mentioned bilingual and, most often, general monolingual dictionaries (unfortunately never learner's dictionaries) play the role of a semanticization 
aid. We failed to find any activities that would indicate information that is not only semantic in nature. Therefore, starting from the language needs and difficulties of their students, the teacher has an essential task to compensate for the shortcomings perceived in textbooks and to use some suggestions from additional material (such as collaborative dictionary creation or creative writing using a dictionary), while developing in students awareness of the importance of the autonomous use of a dictionary, an indispensable tool in lifelong language learning. At the same time, it is advisable to stimulate the use of different types of dictionaries, perhaps the most tried-and-tested and easily accessible online dictionaries (otherwise close to students), with articles emphasizing the observed difficulties of foreign language students.

Key words: dictionary, lexicographic competence, French as a foreign language students, autonomy, teacher.

Primljeno: 13. 5. 2021.

Prihvaćeno: 19. 7. 2021. 